\title{
Real-time factors in the rabbit's nictitating membrane response to pulsed and serial conditioned stimuli
}

\author{
E. JAMES KEHOE and RENÉE M. NAPIER \\ University of New South Wales, Kensington, New South Wales, Australia
}

\begin{abstract}
Conditioning theories and recent real-time models commonly postulate that a reinforcer is signaled by a series of stimuli. In both Pavlovian and operant procedures, serial stimuli have been shown to control the likelihood and timing of responses over intervals of seconds and minutes. The present experiments were conducted to determine whether serial stimuli exercise similar effects over stimulus-reinforcer intervals in the order of hundreds of milliseconds. Such intervals typify those used in conditioning of the rabbit nictitating membrane response. A sequence of four tone pulses (50-100 msec) was used as the CS to assess the effectiveness of serial stimuli. After training with this CS, tests were conducted in which one or more of the pulses were removed. These perturbations of the sequence of stimuli over a 400 -msec interval produced large deficits in CR likelihood and smaller alterations in CR timing. The results are discussed with respect to their implications for current real-time models of conditioning, and particularly with respect to their assumptions about the source of internal stimuli, rules for learning, and rules for generating CRs.
\end{abstract}

Conditioning theories commonly postulate that a reinforcer is signaled by a series of stimuli, not a single discrete event. Pavlov (1927, pp. 103-104) introduced serial stimuli as hypothetical entities to explain "inhibition of delay," in which the lengthening of a conditioned stimulus (CS) prior to the unconditioned stimulus (US) produced a progressive delay in the initiation of the conditioned response (CR). He proposed that the CS initiates a series of distinctive, internal stimulus elements, each of which acquires its own associative strength according to its temporal proximity to the US. Thus, the momentary magnitude of the CR would reflect the associative strength of the current element. Accordingly, the peak magnitude of the CR would appear during the elements closest to the US, and earlier elements remote from the US could even acquire an inhibitory potential. In subsequent accounts of CR generation, serial stimuli have remained a constant feature (Anderson, 1959; Gormezano, 1972; Gormezano \& Kehoe, 1981; Hull, 1937, 1943). Most recently, the serial-stimulus postulate has been adopted in real-time models of conditioning, in which each CS presumably generates a cascade of overlapping stimulus elements (Desmond \& Moore, 1988; Grossberg \& Schmajuk, 1989; Sutton \& Barto, 1990).

Although serial stimuli were originally introduced as hypothetical entities, there is now a substantial literature on the effects of externally imposed serial stimuli on response acquisition (Kehoe, 1982). A variety of inter-

Preparation of this manuscript was supported by Australian Research Council Grant AC89322441. The authors thank Jaimie Cox for his assistance in data collection and Michaela Macrae for her assistance in preparing the manuscript. Correspondence should be sent to E. James Kehoe, School of Psychology, University of New South Wales, P.O. Box 1, Kensington, NSW 2033, Australia. actions among the elements in a series have been identified (see, e.g., Egger \& Miller, 1962; Gaioni, 1982; Kehoe, Marshall-Goodell, \& Gormezano, 1987; Rescorla, 1982). In particular, serial stimuli can gain control over response timing during CS-US intervals that stretch over several seconds or minutes (Boyd \& Levis, 1976; Dubin \& Levis, 1973; Gaioni, 1982; Holland \& Ross, 1981; Matthews \& Lerer, 1987; Newlin \& LoLordo, 1976; Palya, 1985). Likewise, in operant conditioning, the fixedinterval-with-clock schedule also reveals the ability of serial stimuli to control response timing in the range of seconds to minutes (Auge, 1977; Ferster \& Skinner, 1957).

Although serial stimuli influence response generation over intervals of seconds to minutes, there is no corresponding evidence for control by serial stimuli in the range of hundreds of milliseconds. However, such intervals typify the effective CS-US intervals in conditioning preparations such as the rabbit nictitating membrane (NM). This concern with the role of serial stimuli over short intervals addresses two interrelated issues concerning CR generation. First, there is the question of how sensitive the animal is to rapidly changing events that could provide a precise signal for the arrival of the reinforcer. Second, it is unclear what mechanism exercises precise moment-by-moment control over CR generation.

In the rabbit NM preparation, there is very strong temporal control over CRs; both CR likelihood and the time course of individual CRs are highly attuned to the CS-US interval. With regard to CR likelihood, manipulation of the CS-US interval between 0 and $1,000 \mathrm{msec}$ produces a sharply defined concave function in the rate of CR acquisition (see, e.g., Gormezano, Kehoe, \& Marshall, 1983; Smith, Coleman, \& Gormezano, 1969). With regard to the time course of the CR, the CR's time of ini- 
tiation progressively moves away from the US, but the rate of CR recruitment drops so that the maximal extent of the CR-the CR peak-always remains near the US onset (Smith, 1968). Should the CS-US interval be altered, the CR peak will disappear and then reappear at the new locus of the US (Coleman \& Gormezano, 1971; Salafia, Martino, Cloutman, \& Romano, 1979). Furthermore, when a single CS is paired with the US at two randomly mixed intervals, the CR develops two distinct peaks, one located at each locus of US delivery (Hoehler \& Leonard, 1976; Kehoe, Graham-Clarke, \& Schreurs, 1989; Millenson, Kehoe, \& Gormezano, 1977). These features of CR generation are not limited to the rabbit NM response; they appear also in the canine salivary response (Ellison, 1964; Colavita, 1965), human eyeblink response (Suboski, 1967), human galvanic skin response (Kimmel, 1965), and human heart-rate response (Wilson, 1969).

In order to explain the sensitivity of the $\mathrm{CR}$ to the CS-US interval, models directed at NM conditioning have made liberal use of serial stimuli as hypothetical entities. As intervening variables, serial stimuli have repeatedly proved useful in providing a coherent explanation for the effects of the CS-US interval and the time course of the CR (Desmond \& Moore, 1988; Gormezano, 1972; Gormezano \& Kehoe, 1981; Grossberg \& Schmajuk, 1989; Sutton \& Barto, '1981, 1990). However, just as Pavlov's original postulation of hypothetical serial stimuli for long CSs was extended to external stimuli, the models of NM conditioning can also be extended to external stimuli presented within a few hundred milliseconds. In that guise, the conditioning models predict that CRs should be sensitive to perturbations in a series of stimulus elements used during a brief CS-US interval. Generally, the removal of an element should remove sources of associative strength and thus cause noticeable reductions in CR likelihood and alterations in CR timing. In order to test these predictions, in the present experiments a series of four stimulus elements was presented within a brief CS-US intervalspecifically, $400 \mathrm{msec}$. To determine how sensitive the $C R$ is to real-time changes in its external environment, tests were conducted by periodically removing one or more elements from the series.

\section{EXPERIMENT 1}

In Experiment 1, we examined the generation of CRs to a 400 -msec CS containing a sequence of four identical $50-\mathrm{msec}$ pulses of a $1000-\mathrm{Hz}$ tone. This sequence was chosen to approximate a conventional delay CS, such as a constant $400-\mathrm{msec}$ tone. With regard to a serial stimulus hypothesis, each of the four pulses must be encoded in a distinctive fashion so that each pulse will acquire a level of associative strength that will contribute to generating a well-timed CR. This demand is similar to that implicit in a delay CS, in which the animal must develop a discriminable representation for each portion of an externally constant CS.

\section{Method}

Subjects. The subjects were 8 naive, female albino rabbits (Oryctolagus cuniculus), each 70-80 days old and weighing approximately $1.5 \mathrm{~kg}$ on arrival from the university's breeding unit. The animals had free access to food and water in their home cages.

Apparatus. The apparatus and recording procedure for the NM response, which were patterned after those of Gormezano (1966), are detailed by Kehoe, Feyer, and Moses (1981). The CS was a series of four identical 50-msec pulses, each being an 85-dB (SPL, $\mathrm{C}$ scale) $1000-\mathrm{Hz}$ tone superimposed on an ambient noise level of $81 \mathrm{~dB}$. Each pulse was separated from the next by $50 \mathrm{msec}$. The US was a 50-msec, 3-mA, 50-Hz electrotactile pulse delivered via 9-mm stainless steel Autoclip wound clips positioned $10 \mathrm{~mm}$ apart and $15 \mathrm{~mm}$ posterior to the dorsal canthus of the right eye. The sequence and timing of stimulus events were controlled by an Apple II computer equipped with interfaces and software developed by Scandrett and Gormezano (1980).

To monitor movements of the NM, a small tinned copper wire hook was attached to a silk loop sutured in the NM of the rabbit's right eye. The other end of the hook contained a loop that fitted over the curved end of an L-shaped piano-wire crank, which operated a photoelectric transducer (Gormezano \& Gibbs, 1988). The signal from the transducer was amplified and transmitted to an analog/digital converter installed in the computer. No straps were used to restrain the external eyelids.

Procedure. All rabbits received 1 day of preparation, 2 days of recovery, 1 day of adaptation, and 7 days of training. On the preparation day, hair posterior to the rabbit's right eye was shaved, a small loop of silk (000 Dynex) was sutured into the NM, and the animals were returned to their home cages for 2 days of recovery. On the adaptation day, the animals were placed in the conditioning apparatus for $60 \mathrm{~min}$, but neither a CS nor a US was presented. Following adaptation, the animals received 4 days of training, each containing $80 \mathrm{CS}$-US trials. The CS-US interval was $400 \mathrm{msec}$, measured from the onset of the first tone pulse to the onset of the US. On Days 5-7, all animals received $80 \mathrm{CS}-\mathrm{US}$ trials plus $16 \mathrm{CS}$-alone test trials. A test trial was administered every 6 th trial. There were two presentations each of eight different types of test trials. Four of the trial types entailed a progressive addition of pulses to reconstitute the full CS, namely one (A), two (AA), three (AAA), or four successive pulses (AAAA). The remaining four trial types were doublets or triplets of pulses, in which intermediate pulses were deleted, namely, A-A, $\mathrm{A}-\mathrm{A}, \mathrm{AA}-\mathrm{A}$, and A-AA. The test trials were arranged so that one of each type was presented before there were any repetitions. The mean intertrial interval (ITI) was $45 \mathrm{sec}$ (range 40-50 sec).

Response definition. A CR was defined as any extension of the NM exceeding $0.5 \mathrm{~mm}$ initiated during the 400 -msec CS-US interval. On CS-alone trials, a CR was any extension of the NM exceeding $0.5 \mathrm{~mm}$ initiated within $800 \mathrm{msec}$ following CS onset.

\section{Results}

Unless otherwise noted, planned contrasts were used to analyze the data, and the rejection level was set according to a Type I error rate of 0.05 .

CR likelihood. The percentage CRs on each type of test trial are shown in Figure 1, collapsed across Days 5-7. Each bar, which represents the total CR likelihood, is divided into two portions. The lower portion depicts the likelihood of anticipatory CRs-that is to say, CRs initiated during a 400-msec interval following CS onset, which thus would have preceded the US on CS-US trials. The upper portion depicts the remaining late CRs initiated after the 400 -sec interval had elapsed. 
Inspection of Figure 1 reveals that the initial pulse (A) had a substantial CR-evoking capability, yielding a total CR likelihood of $58 \%$ CRs. Nevertheless, the addition of further pulses to complete the CS (AAAA) produced progressive increments in the recruitment of CRs, yielding total CR likelihoods of $69 \%, 77 \%$, and $96 \%$ CRs for AA, AAA, and AAAA, respectively [linear $F(1,7)=$ 6.89]. Among the total $C R s$, the vast majority were anticipatory in nature, and hence, the analysis of anticipatory CRs showed the same pattern of increments [linear $F(1,7)=14.66]$

Whereas the number of pulses had a pronounced effect on CR likelihood, the temporal pattern of pulses had a more modest effect. The pulse doublets, AA, A-A, and A--A, yielded total CR likelihoods of $69 \%, 85 \%$, and $66 \%$ CRs, which formed an inverted-U function for the delay between the first and second pulse [quadratic $F(1,7)$ $=6.03$ ]. When consideration is restricted, however, to anticipatory CRs, the level of responding declined for the $\mathbf{A}-\mathbf{A}$ and $\mathbf{A}--\mathbf{A}$ doublets relative to the AA doublet. In agreement with this observation, there was a significant downward linear trend across the means of $61 \%, 62 \%$, and $39 \% \mathrm{CRs}$, for AA, A-A, and A--A, respectively [linear $F(1,7)=6.77$ ]. Thus, as the second pulse was delayed, the evocation of additional CRs was also delayed so that many started after the 400 -msec anticipatory interval had elapsed. Among the pulse triplets (AAA, A-AA, and $\mathrm{AA}-\mathrm{A}$ ), there was generally a high level of total responding ( $M=83 \% C R s)$ and a uniformly lower level of anticipatory responding ( $M=67 \% \mathrm{CRs}$ ). Any differences among the temporal arrangements of the three pulses failed to attain statistical significance.

CR topography. Figure 2 depicts the time course of CRs derived from test trials on which the NM extension exceeded the $0.5-\mathrm{mm}$ criterion for a CR. The top panel shows the CRs generated on A, AA, AAA, and AAAA trials. The middle panel shows the CRs generated by doublets, AA, A-A, and A--A, and the bottom panel shows CRs to the triplets, AAA, AA-A, and A-AA. The average $C R$ topography curves were constructed from the

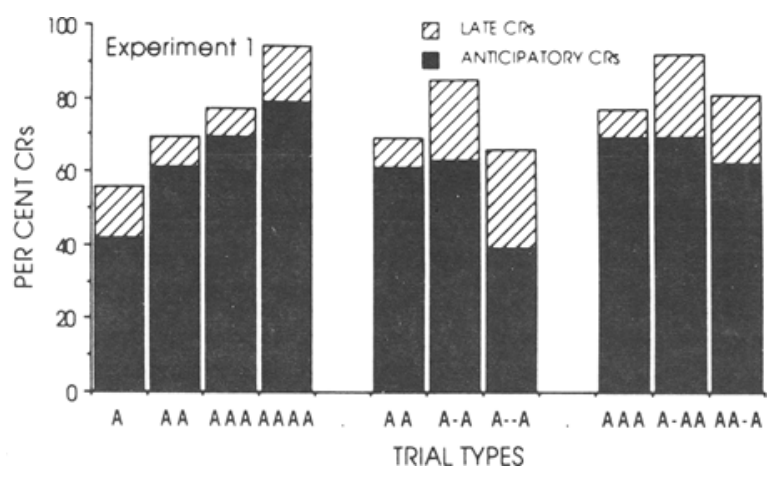

Figure 1. Percentage CR as a function of trial types in Experiment 1. (Total CRs are divided into anticipatory CRs, which were initiated within 400 msec after CS onset, and late CRs, which were initiated more than $\mathbf{4 0 0}$ msec after CS onset.)
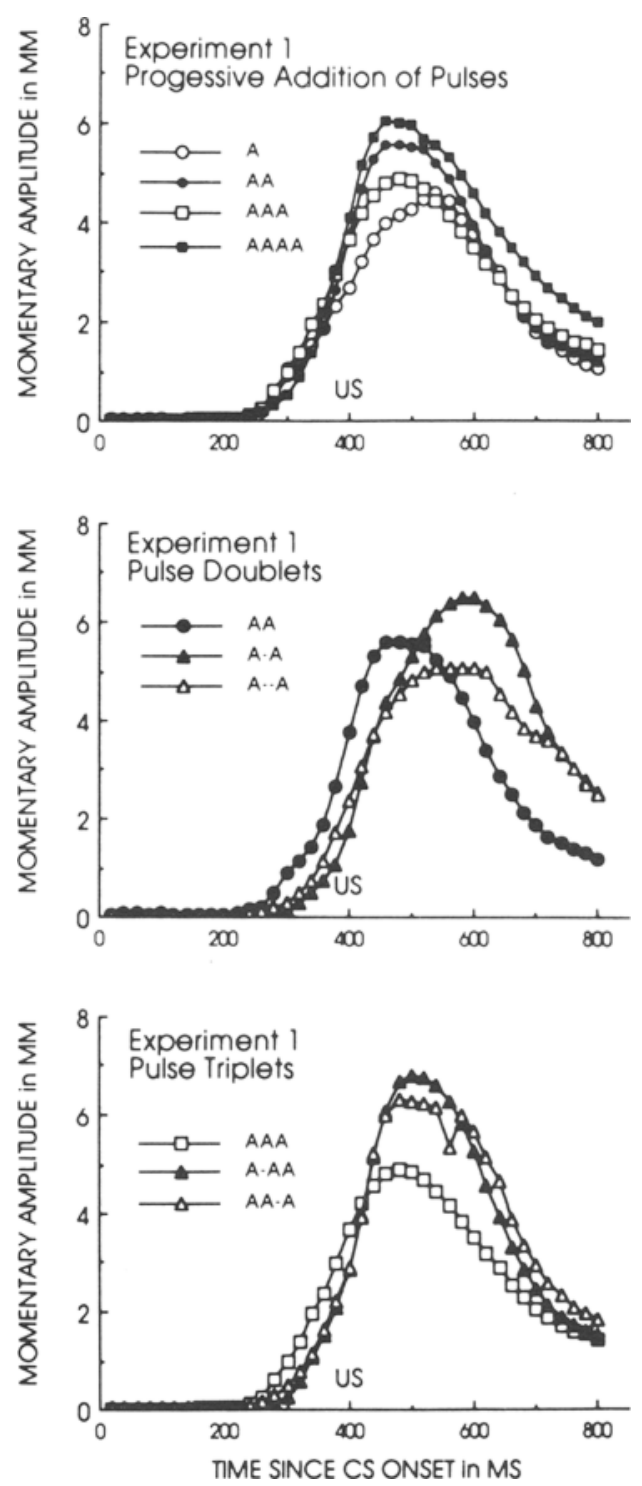

Figure 2. Time course of CRs in Experiment 1. (Group mean momentary amplitude of the nictitating membrane at $20-\mathbf{m s e c}$ intervals following onset of the CS. The top panel shows the CRs generated on A, AA, AAA, and AAAA trials. The middle panel shows the CRs generated by doublets, $A A, A-A$, and $A--A$, and the bottom panel shows $C R s$ to the triplets, $A A A, A A-A$, and $A-A A$.)

momentary NM extension at successive time points spaced at 20-msec intervals following CS onset. Because the curves are based on all CRs, some subjects contributed more CRs than others did. As aggregates over both trials and subjects, the group topographies are thus best viewed as the envelopes within which individual CRs occurred.

As can be seen in Figure 2, CR topography varied with the pattern of tone pulses. Any apparent differences in amplitude failed to reach significance, but the timing of the CRs was altered to some extent. Examination of the top panel reveals that the peak of the CR moved to the right as the number of pulses was reduced. Among the doublets shown in the middle panel, the progressive lengthening of 


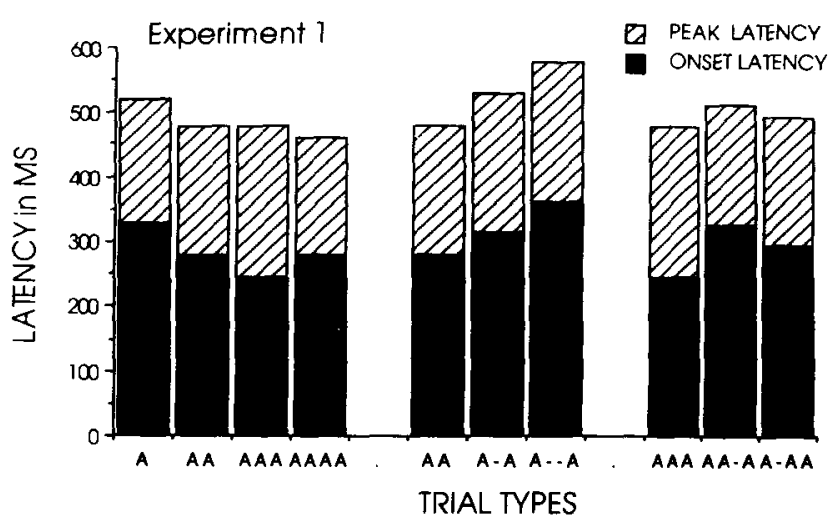

Figure 3. Group mean latencies as a function of trial types in Experiment 1. (The bottom portion of each bar shows the mean CR onset latency, and the upper portion of each bar shows the mean CR peak latency.)

the interval between the first pulse and the second pulse also moved the peak of the CR to the right, away from the point of US delivery. Among the pulse triplets, the placement of the CR peak showed only a small delay as the second and third pulses were delayed relative to the first pulse.

To ascertain the effects of the pulse combinations on CR timing, analyses were conducted for both the point of CR initiation (CR onset latency) and the point of maximal CR amplitude (CR peak latency). The mean latencies for different pulse combinations are shown in Figure 3 . The bottom portion of each bar represents the mean $\mathrm{CR}$ onset latency, and the upper portion represents the mean CR peak latency. Subjects' contributions to the mean latencies were equally weighted, in contrast with the contributions to the aggregate topographies.

As can be seen in the aggregate topographies, there were modest alterations in CR timing for different numbers of pulses. The single pulse (A) tended to produce the longest latencies. As pulses were added, both onset latency and peak latency decreased by approximately 55 msec. Statistical comparisons across A, AA, AAA, and AAAA test trials yielded only a significant quadratic trend for onset latency $[F(1,7)=13.37]$.

Among the pulse doublets, the alterations in $\mathrm{CR}$ timing were more pronounced. For the AA, A-A, and A-- A trials, the mean onset latencies were 277,311 , and $360 \mathrm{msec}$, respectively. The onset latency for AA was identical to that of the complete AAAA sequence $(M=$ $277 \mathrm{msec}$ ). Thus, as the second pulse was delayed relative to the first pulse, there was a progressive and significant delay in CR initiation [linear $F(1,7)=6.36$ ]. The timing of the $C R$ peak also showed a progressive delay. For the pulse doublets, AA, A-A, and A--A, the mean peak latencies were 475,526 , and $575 \mathrm{msec}$, respectively [linear $F(1,7)=36.36$ ]. Among the triplets, there was a significant increase in onset latency as the second and third pulses were progressively delayed [linear $F(1,7)=$ 9.09]. Specifically, for AAA, AA-A, and A-AA, the mean onset latencies were 245,325 , and $294 \mathrm{msec}$. The apparent quadratic trend across the means failed to reach significance. For peak latency, the linear and quadratic trends across pulse triplets were smaller than those seen in onset latency and failed to reach significance.

\section{Discussion}

The present experiment revealed that the likelihood and timing of CRs were influenced by alterations in the sequence of pulses that constituted the CS. CR likelihood was most dramatically affected, showing large reductions as pulses were subtracted from the CS. For example, compared with 96\% CRs recruited by all four pulses (AAAA), the total percentage $C R$ recruited by one pulse (A) was $58 \%$. The alterations in timing of the CR were more modest. In particular, progressive delays in CR timing were seen when the interval between a pair of pulses was increased.

From another perspective, the conditioning system tolerated the manipulations reasonably well. For example, even when three quarters of the pulses were eliminated, one pulse could still reliably recruit a majority of the CRs produced by the entire sequence. When CRs did occur, their maximum amplitude remained much the same, and timing was delayed but not grossly inaccurate. For example, the increase in CR peak latency from the closely spaced AA doublet to the most widely spaced A-- $\mathrm{A}$ doublet was $100 \mathrm{msec}$. Hence, the first pulse in the sequence appeared to initiate an interval representation with considerable, although not complete, control over the recruitment and timing of CRs.

From the vantage point of a serial stimulus hypothesis, the partial sensitivity of responding to perturbations in an external sequence of stimuli provides some indirect evidence that a corresponding internal sequence underlies CR generation by conventional, constant CSs. If responding depended entirely on the external sequence, the manipulations of the pulse train would have produced greater alterations in the CR. Conversely, if responding were independent of the external sequence, then the manipulations would have had no effect on either CR likelihood or timing.

The results of Experiment 1 leave open several questions regarding the effects of the external manipulations on CR performance, particularly their effects on CR likelihood. The available serial stimulus hypotheses commonly distinguish two functions for a stimulus series-namely, an associative function and a dynamogenic function-both of which determine responding on a moment-by-moment basis (Anderson, 1959; Desmond \& Moore, 1988; Gormezano, 1972; Grossberg \& Schmajuk, 1989; Hull, 1943; Sutton \& Barto, 1981). First, each stimulus element is presumed to command a separate associative strength. For example, Hull's (1943) trace hypothesis assumes that the segment of the trace most contiguous to the US directly acquires associative strength, and that other segments command associative strength via stimulus generalization. Other accounts allow for second-order conditioning among serial elements (Sutton \& Barto, 1981, 1990). Second, with regard to the dynamogenic factor, the intensity of each element is presumed to energize responding in a multiplicative fashion with associate strength. Hull's (1943) 
account was explicit on this point, and the recent real-time models allow for that eventuality. In the present results, the effects of subtracting pulses would have removed both associative and dynamogenic support for CR performance.

Although the associative and dynamogenic contributions by each pulse to the CR remain uncertain, the pulses appeared to have each been encoded in a distinctive fashion. Specifically, the pulsed CS could be regarded as the repeated presentation of the same stimulus at four different CS-US intervals, namely $400,300,200$, and $100 \mathrm{msec}$. Had training been conducted with a single-pulse CS but with separate trials at each CS-US interval, such a CS would have elicited a CR with four peaks, each located near one of the points of US delivery (cf. Hoehler \& Leonard, 1976; Kehoe et al., 1989; Millenson et al., 1977). By the same token, if the animals in the present study had encoded all the pulses in an identical fashion, then a single pulse (A) should have elicited a CR with four peaks, one each at approximately 100,200,300, and 400 msec after the pulse's onset. In fact, no single pulse or combination of pulses elicited more than one peak, and that peak was located 400-600 msec after CS onset.

If the successive pulses were encoded as distinctive CSs, then the processes seen in conditioning with longer serial stimuli may explain the predominance of the CR topography conforming to the $400-\mathrm{msec} C S-U S$ interval of the first pulse. In particular, there is a temporal primacy effect in serial stimuli, in which the first element comes to command substantial responding to the apparent detriment of later elements (see, e.g., Egger \& Miller, 1962; Gaioni, 1982; Kehoe, 1979; Wickens, 1959, 1965). However, it is not clear whether the resemblance between the present pulse series and a serial stimulus with distinctive elements is superficial or otherwise. Particularly, it is unknown whether the distinctive elements in a series evolve CR topographies appropriate to their CS-US intervals or to the first element's CS-US interval.

\section{EXPERIMENT 2}

In Experiment 2, the stimulus comprised distinctive auditory elements. Thus it was possible to test each element individually and ascertain its CR-generating characteristics, as well as to do the same when the element was in combination with other elements.

\section{Method}

The subjects were 16 naive, female albino rabbits. Except where noted, the apparatus and procedure were identical to those in Experiment 1 . All rabbits received 1 day of preparation, 2 days of recovery, 1 day of adaptation, and 7 days of training. The animals were assigned randomly to two groups $(n=8)$, which were designated Groups Ascending and Descending. Both groups were trained with a CS that contained a sequence of four $100-\mathrm{msec} 85-\mathrm{dB}$ (SPL, C scale) auditory stimuli, which were followed by the US at the offset of the fourth element. In Group Ascending, half the animals were trained with the sequence of tones arranged in ascending frequency-specifically, $400,1800,3300$, and $4800 \mathrm{~Hz}$. The other half of the animals were trained with a different ascending sequence composed of a $400-\mathrm{Hz}$ tone, a $1600-\mathrm{Hz}$ tone, a $4800-\mathrm{Hz}$ tone, and a white noise. In Group Descending, the sequences were reversed; they were, specifically, 4800-, 3300-, 1800, and $400-\mathrm{Hz}$ tones for half the animals, and white noise, 4800-, 1600-, and 400- $\mathrm{Hz}$ tones for the other half of the animals. In both groups, the four elements in the sequence were labeled $A, B, C$, and $D$.

On Days 1-4, each session contained $80 \mathrm{CS}$-US trials. On Days 5-7, 16 unreinforced test trials were added, two each of $A, A B, A B C$, $A B C D, B, C, D$, and DCBA. The tests of $A, A B, A B C$, and $A B C D$ entailed the progressive addition of the elements that made up the complete CS on CS-US trials. The tests of B, C, and D were tests for $C R$ generation by the individual elements. The test of the reverse sequence, DCBA, provided an arrangement of all four elements that differed dramatically from the original sequence. A test trial was administered after every fifth CS-US trial. The test trials were administered in the order listed above for the first half of the session and in the reverse order for the second half of the training session. The observation interval was extended to $800 \mathrm{msec}$ following CS onset on test trials. The mean ITI was $45 \mathrm{sec}$ (range, $40-50 \mathrm{sec}$ ).

\section{Results}

CR likelihood. The total CR likelihood on test trials is shown in Figure 4, divided into anticipatory CRs and late CRs. There were distinct differences in the recruitment of CRs as the successive elements were added to reconstitute the CS (ABCD). In Group Ascending, each element played an appreciable role in total $C R$ recruitment. The $A$ element itself evoked CRs with a moderate likelihood $(M=31 \%$ CRs). The addition of $\mathrm{B}$ to create the $\mathrm{AB}$ sequence produced an increment in CR likelihood up to $60 \% \mathrm{CRs}$. The $A B C$ and $A B C D$ sequences produced progressively higher
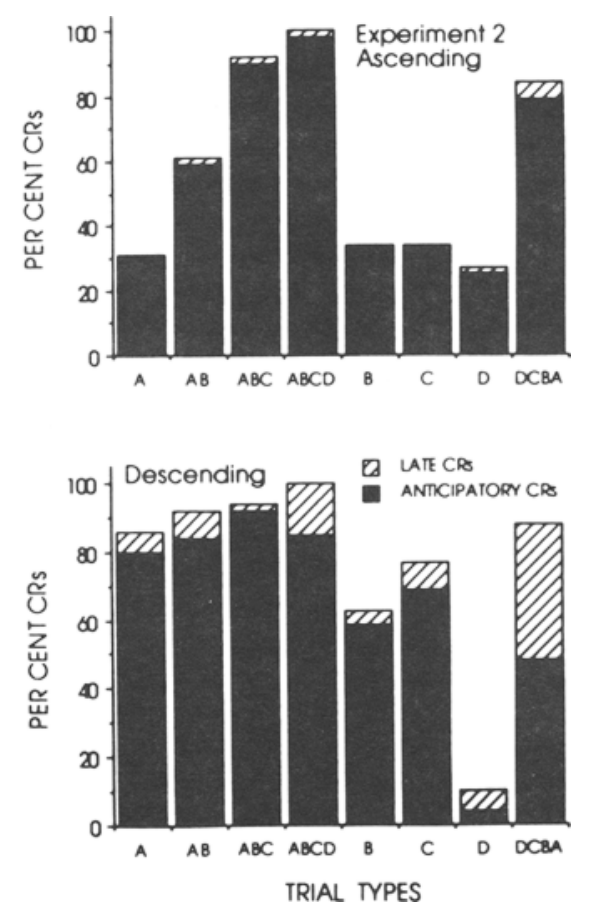

Figure 4. Percentage CR as a function of trial types in Experiment 2. (Total CRs are divided into anticipatory CRs, which were initiated within 400 msec after CS onset, and late CRs, which were initiated more than 400 msec after CS onset. The top panel shows the means for Group Ascending, and the bottom panel shows the means for Group Descending.) 
means of $92 \%$ and $100 \%$ CRs, respectively. A similar pattern emerged in Group Descending, but the A element evoked CRs with a very high likelihood ( $M=86 \%$ CRs). Thus, the addition of later elements to create $A B, A B C$, and $A B C D$ could only produce relatively small increases to means of $92 \%, 94 \%$, and $100 \%$ CRs, respectively. Statistical comparisons for total CRs yielded a significant linear trend across $\mathrm{A}, \mathrm{AB}, \mathrm{ABC}$, and $\mathrm{ABCD}[F(1,12)=$ $24.86]$, which interacted with groups $[F(1,12)=11.41]$. Because nearly all the CRs were anticipatory, the separate analysis of anticipatory CRs yielded the same results.

Figure 4 also reveals that there was a partial tradeoff in the CR-evoking ability of the individual elements. In Group Ascending, the elements all possessed a relatively uniform moderate capacity to recruit CRs. Specifically, A, B, C, and D yielded total response levels of $31 \%, 33 \%$, $33 \%$, and 27\% CRs, respectively. In Group Descending, however, there appeared to be a sharp decline in the relative CR-evoking capabilities of the individual elements, particularly for the $400-\mathrm{Hz}$ tone D element. For A, B, C, and $D$, the total levels were $86 \%, 62 \%, 77 \%$, and $10 \%$ CRs, respectively. Statistical comparisons revealed a linear trend across total responding to $A, B, C$, and $D[F(1,12)=$ $20.99]$, which interacted with groups $[F(1,12)=16.63]$.

The reversed sequence (DCBA) produced substantial CR evocation, although not as greatly as did the training sequence $(A B C D)[F(1,12)=16.62]$. Specifically, in Groups Ascending and Descending, DCBA yielded total levels of $83 \%$ and $88 \%$ CRs, respectively, compared to the $100 \%$ CR levels yielded by the ABCD sequence in both groups. Although in Group Descending only about half the CRs were anticipatory, an analysis of anticipatory CRs failed to yield a significant interaction of groups $\times$ test sequence (ABCD vs. DCBA) $[F(1,12)=2.42, p>.10]$.

CR topography. Figure 5 depicts the time course of CRs on test trials. The top row of panels shows the CRs generated on $A, A B, A B C$, and $A B C D$ trials. The middle row shows the CRs generated by the individual elements A, B, C, and D. The bottom row shows the CRs generated by the reversed sequence (DCBA) versus the training sequence $(A B C D)$. For purposes of statistical comparison, the mean onset latencies and peak latencies
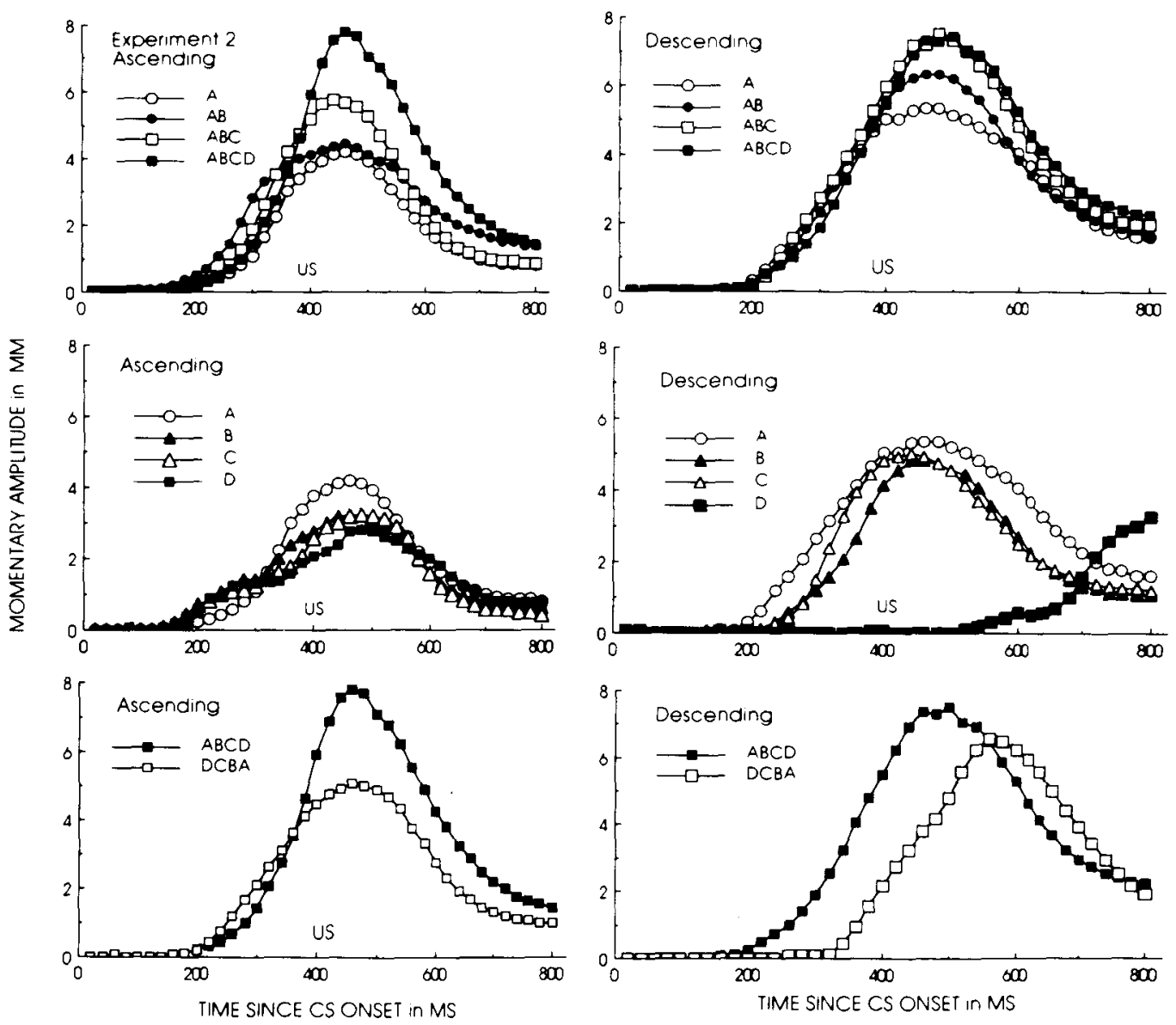

Figure 5. Time course of CRs in Experiment 2. (Group mean momentary amplitude of the nictitating membrane at 20-msec intervals following onset of the CS. The top panels show the CRs generated on $A, A B, A B C$, and $A B C D$ trials. The middle panels show the $C R$ generated on $A, B, C$, and $D$ trials. The bottom panels show the CRs generated on ABCD and DCBA trials. The left panels show the means for Group Ascending, and the right panels show the means for Group Descending.) 

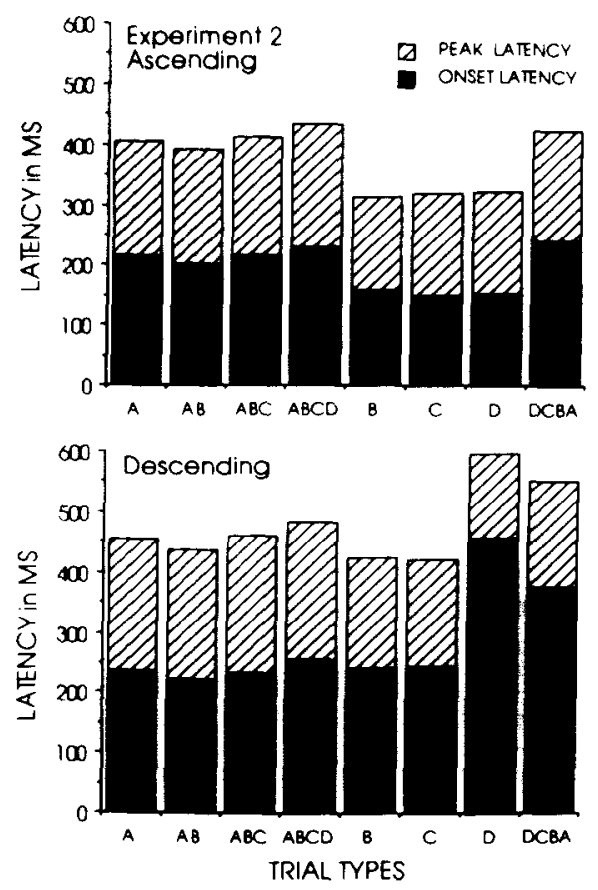

Figure 6. Group mean latencies as a function of trial types in Experiment 2. (The bottom portion of each bar shows the mean CR onset latency, and the upper portion of each bar shows the mean CR peak latency. The top panel shows the means for Group Ascending, and the bottom panel shows the means for Group Descending.)

are shown in Figure 6 for the different types of test trials for Groups Ascending and Descending.

Examination of the top panel of Figure 5 reveals that the progressive addition of elements to form the full $A B C D$ sequence altered the amplitude of the $C R$ in a manner that paralleled the results for CR likelihood. That is to say, A, $\mathrm{AB}, \mathrm{ABC}$, and $\mathrm{ABCD}$ generally produced progressively greater $C R$ amplitudes. Across both groups, the mean amplitudes for $A, A B C, A B C$, and $A B C D$ were 4.8, 4.6, 6.1, and $6.2 \mathrm{~mm}$, respectively [linear $F(1,12)=7.81$ ]. Group Ascending showed larger differences than did Group Descending; these differences appeared statistically as an interaction among their quadratic trends $[F(1,12)=4.75]$.

Notwithstanding the differences in likelihood and amplitude, the time course of the CRs appeared relatively uniform. Across both groups, A, AB, ABC, and ABCD produced mean onset latencies of $225,211,224$, and $243 \mathrm{msec}$, respectively. Although the differences were small, there was in fact a significant linear increase in CR onset latency as elements were added $[F(1,12)=$ 13.48]. This increase reflects the contribution of CRs recruited by later elements in the series. The location of the peak occurred shortly after the point of US delivery; the overall mean peak latencies for $A, A B, A B C$, and $A B C D$ were $430,412,434$, and $458 \mathrm{msec}$, respectively.

As is depicted in the middle row of panels, the topographies produced by the separate A, B, C, and D elements showed similar amplitudes but did display some variance in time course. For A, B, C, and D, the overall mean am- plitudes were $4.8,3.4,4.2$, and $3.0 \mathrm{~mm}$, respectively. The apparent downward linear trend approached but failed to reach statistical significance $[F(1,12)=4.34, p<.10]$. Any differences among groups also failed to attain significance. With regard to $C R$ timing, the differences were not as great as might have been expected from the differences in their individual CS-US intervals, which were 400 , 300,200 , and $100 \mathrm{msec}$, respectively. Nevertheless, there were substantial differences in CR timing across the separate elements, which interacted with the groups. Specifically, there were linear and quadratic trends that interacted with the groups in both onset latency $[F \mathrm{~s}(1,12)=29.31$ and 7.09] and peak latency $[F \mathrm{~s}(1,12)=13.09$ and 7.68]. In Group Ascending, the latencies for the $\mathrm{B}, \mathrm{C}$, and D elements were foreshortened by more than $60 \mathrm{msec}$ relative to the latency for the A element. As can be seen in Figure 6, $B, C$, and D produced mean peak latencies of 313,318 , and $321 \mathrm{msec}$, compared with the mean peak latency of $405 \mathrm{msec}$ for A. In Group Descending, A, B, and C produced similar latencies, whereas the latencies of the few CRs produced by $D$ were extended by more than $150 \mathrm{msec}$.

As can be seen in the bottom row of Figure 5, the reverse sequence of elements (DCBA) generally evoked a CR similar in form to that for the training sequence (ABCD). In Group Ascending, the CR for DCBA was smaller than that for $A B C D$. However, the apparent difference in peak amplitudes for DCBA $(M=5.1 \mathrm{~mm})$ and $\mathrm{ABCD}(M=6.1 \mathrm{~mm})$ approached but failed to reach statistical significance $[F(1,12)=4.38, p<.10]$.

Although the order of stimuli was reversed on DCBA trials, CR peaks appeared after rather than before the 400-msec point. In Group Descending, DCBA's time course was displaced approximately $100 \mathrm{msec}$ from that of ABCD. Otherwise, CRs to DCBA followed the same time course as that of CRs to ABCD. The displacement of CRs to DCBA appears entirely attributable to D's failure to acquire any discernible CR-evoking capability. These observations were confirmed by a significant interaction of test sequence (DCBA vs. ABCD) $\times$ groups in both onset latency $[F(1,12)=9.57]$ and peak latency $[F(1,12)=5.72]$. In Group Ascending, DCBA yielded a mean onset latency of $241 \mathrm{msec}$ and a mean peak latency of $423 \mathrm{msec}$, which were very similar to those for $A B C D$, which were 216 and $435 \mathrm{msec}$, respectively. However, in Group Descending, DCBA yielded a mean onset latency of $376 \mathrm{msec}$, a substantial increase over the mean onset latency of $234 \mathrm{msec}$ for ABCD. Likewise, the DCBA's mean peak latency of $550 \mathrm{msec}$ was longer than the $481 \mathrm{msec}$ for $\mathrm{ABCD}$.

\section{Discussion}

In agreement with the findings of Experiment 1, the present results indicated that CR generation was sensitive to perturbations in the four brief elements that constituted the serial CS. In the ascending series, there was a direct relation between the CR likelihood and the number of elements in the test series; each element by itself yielded around $30 \%$ CRs. In the descending series, the direct relation was weaker, because the first element $(\mathrm{A})$ 
produced a very high $C R$ likelihood $(M=86 \% C R s)$, leaving little room for observation of contributions by the later elements. However, by themselves, the B and C elements evoked about $70 \%$ CRs, but the $D$ element, the $400-\mathrm{Hz}$ tone, evoked only $10 \%$ CRs. In both the ascending and the descending series, when CRs did occur, their timing was surprisingly resistant to perturbations in the element sequence, including a reversal of the sequence. Although there were some alterations, the largest displacement in timing could be ascribed to the weak CR-evoking capabilities of the D element in Group Descending.

The present findings provide evidence that processes identified in more prolonged serial stimuli may operate in the more compact sequence of elements making up the present CS (see Kehoe, 1982). Specifically, processes of temporal primacy and perhaps generalization appeared prominent in determining the time course of CRs. In both the ascending and the descending sequences, the first element (A) and its 400-msec CS-US interval governed the time course of CRs to the later elements. Had the CR to each element been determined by its own CS-US interval, the individual tests for the B, C, and D elements should have yielded CRs with peaks at approximately 300 , 200 , and $100 \mathrm{msec}$ after the elements' onsets. In Group Ascending, the CR latencies for the B, C, and D elements were only foreshortened by $80 \mathrm{msec}$, compared to A's latency. Because this apparent generalization of the topography of CRs extended across a substantial portion of the tonal frequency dimension plus white noise, the animals may have been generalizing more on the basis of the stimulus onset properties than on that of their tonal frequency. If onset properties were the sole basis of generalization, the cumulative effect of CR generation produced by adding $\mathrm{B}, \mathrm{C}$, and D would be duplicated by repeating any of the elements two, three, or four times.

\section{EXPERIMENT 3}

Experiment 3 was designed with two aims stemming from questions raised by the previous findings. First, we wished to ascertain whether there were any cumulative effects of repeating the training element. Second, we wished to ascertain the degree of generalization among the auditory stimuli used as elements in Experiment 2.

With regard to issues of cumulative effects, the results of both Experiments 1 and 2 revealed that subtraction of elements from the CS generally yielded reductions in the recruitment of CRs and some alterations in CR timing. This finding suggested that there is an additive effect of the successive elements, which could arise from both their associative and their dynamogenic properties. As a test for such additive effects, in the present experiment we used a single 50-msec pulse as the CS in a trace-conditioning paradigm, in which there were interspersed tests with one, two, three, or four successive presentations of the training CS.

With regard to the question of generalization, the tones used in Experiment 2 encompassed the full range of frequencies that have been used in both aversive and appetitive conditioning with the rabbit (Chisholm, Hupka, \& Moore,
1969; Moore, 1972; Poulos, Kehoe, \& Gormezano, 1985). Generalization tests conducted with stimuli grouped around a training stimulus from the middle of the range (e.g., $1200 \mathrm{~Hz}$ ) yielded a clear decremental gradient. For example, in Moore (1972), tests with CSs of 400, 800, 1200 $(\mathrm{CS}+), 1600$, and $2900 \mathrm{~Hz}$ yielded approximately $24 \%$, $47 \%, 58 \%, 37 \%$, and $21 \%$ CRs, respectively. However, the results of Experiment 2 suggested that there may be a relatively flat generalization gradient among the tones used. Such a flattened gradient could occur because the duration of the elements was only $100 \mathrm{msec}$, which is brief compared with the CS durations between 250 and $750 \mathrm{msec}$ found in the published studies of generalization and differentiation. The brief duration of the elements may have encouraged generalized responding based on onset properties rather than on tonal frequency. In fact, there is evidence from differential conditioning studies that increasing CS duration from 250 to $750 \mathrm{msec}$ facilitates discriminative responding, implying a reduction in generalized responding among CSs (Chisholm et al., 1969). Accordingly, in Experiment 3 we examined generalization among brief tones.

\section{Method}

The subjects were 8 naive female albino rabbits. Except where noted, the apparatus and procedure were identical to those in Experiment 1 . All rabbits received 1 day of preparation, 2 days of recovery, 1 day of adaptation, and 11 days of training. The animals were assigned randomly to two groups $(n=4)$ designated as Group 400 and Group 4800 according to the frequency of the tone used as the training stimulus. On CS-US trials, the CS was a 50-msec 85-dB (SPL, $\mathrm{C}$ scale) tone, and the CS-US interval (onset to onset) was $400 \mathrm{msec}$. Each session contained $80 \mathrm{CS}$-US trials and 16 test trials. For determining whether successive pulses yielded an additive effect, there were two trials each of two, three, and four successive 50 -msec pulses of the training CS. Each pulse was separated from the next by $50 \mathrm{msec}$. The training $C S$ was labeled as $A$, and the test trials for two, three, and four pulses were labeled AA, AAA, and AAAA, respectively. For purposes of generalization testing, Group 400 received two trials each of $400-, 1800-, 3300$, and $4800-\mathrm{Hz}$ tones, which were designated A, B, C, and D, respectively. For Group 4800 , the A, B, C, and D test stimuli were the 4800-, 3300-, 1800 , and $400-\mathrm{Hz}$ tones, respectively. Both groups were also tested with the white noise. After every fifth CS-US trial, a test trial was administered in which one of each type appeared before there were any repetitions. The ITI was $45 \mathrm{sec}$ (range 40-50 sec).

\section{Results}

CR likelihood. Total CR likelihood on each type of test trial is shown in Figure 7, across Days 7-10 and collapsed over Groups $\mathbf{4 0 0}$ and 4800 . Inspection of Figure 7 reveals that the repetition of the training $C S$ (A) for two (AA), three (AAA), or four (AAAA) times yielded a progressive reduction in the likelihood of $C R s$. The reduction appeared to be more pronounced for anticipatory CRs, but it was attended by considerable variation and thus failed to attain significance [linear $F(1,6)=5.19, p<.10]$. When late CRs were included, the reduction was smaller but less variable, and it did attain significance [linear $F(1,6)=10.67]$. Differences between the two groups were small and failed to attain significance.

Despite the brevity of the CS $(50 \mathrm{msec})$, there was a decremental generalization gradient across the A, B, C, 


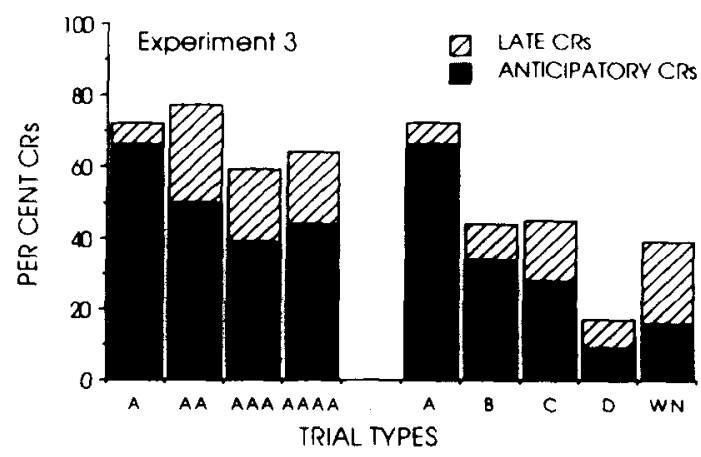

Figure 7. Percentage CR as a function of trial types in Experiment 3. (Total CRs are divided into anticipatory CRs, which were initiated within $\mathbf{4 0 0}$ msec after CS onset, and late CRs, which were initiated more than $\mathbf{4 0 0}$ msec after CS onset.)

and D test stimuli for both anticipatory CRs and total CRs [linear $F_{\mathrm{s}}(1,6)=19.93$ and 19.22]. Although there was a significant generalization gradient, even the most remote test stimulus (D) and the white noise (WN) still yielded appreciable levels of responding, particularly when late CRs were included. Differences between the two groups were small and failed to attain significance.

CR topography. The time course of CRs on test trials is shown in Figure 8, across Days 7-10 and collapsed over the two groups. The top panel reveals that the addition of extra pulses beyond the single pulse used in training had minimal consequences for the amplitudes, which were $2.5,2.0,3.2$, and $3.0 \mathrm{~mm}$, respectively. The apparent
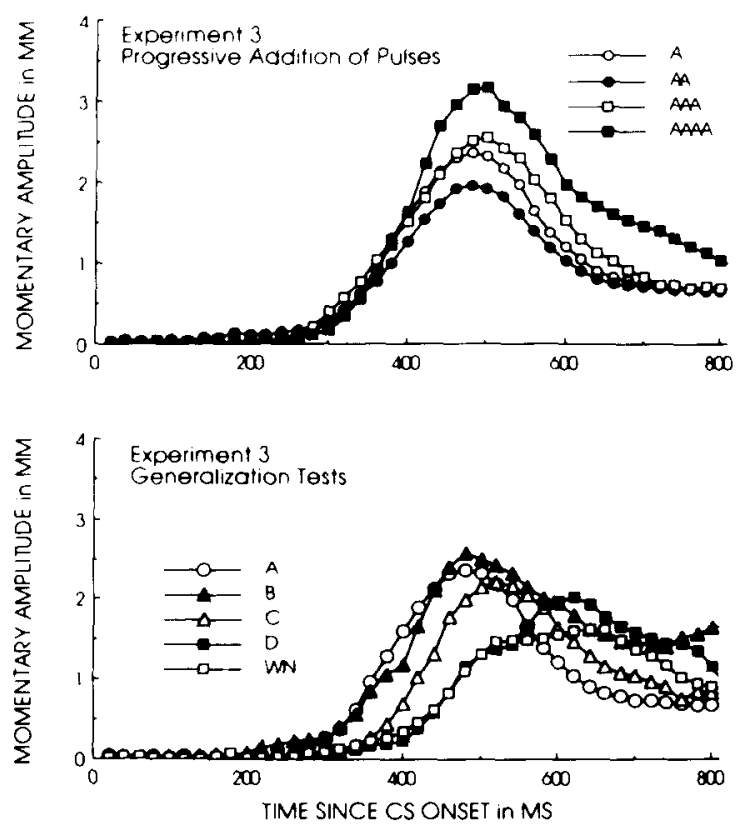

Figure 8. Time course of CRs in Experiment 3. (Group mean momentary amplitude of the nictitating membrane at $20-\mathrm{msec}$ intervals following onset of the CS. The upper panel shows the CRs generated on A, AA, AAA, and AAAA trials, and the lower panel shows the CRs generated on $A, B, C, D$, and $N$ trials. increase in amplitude failed to approach statistical significance [linear $F(1,6)=2.13, p>.10$ ]. Any apparent differences in onset latency or peak latency were unsystematic and failed to approach statistical significance.

The lower panel of Figure 8 reveals that a generalization decrement appeared in CR amplitude. For the A, B, $C$, and $D$ test stimuli, the mean amplitudes were $2.5,3.6$, 1.8 , and $0.7 \mathrm{~mm}$, respectively [linear $F(1,6)=25.98$ ] Although it appeared that the $B$ test stimulus produced a larger CR than the A training stimulus did, the quadratic trend across stimuli missed reaching significance $[F(1,6)=$ $3.81, p<.10]$. Notwithstanding the differences in amplitude, any apparent differences in CR timing were small and failed to approach significance.

\section{Discussion}

One of our aims in Experiment 3 was to assess the effect of repeating a training element on $C R$ generation. In Experiments 1 and 2, one plausible explanation of the deleterious effects of removing elements for a training CS had been the potential loss of their additive contributions to responding. According to an additive hypothesis, each repetition of the training element should have increased CR likelihood. In fact, the present results indicated that the repetition of a training element had a deleterious effect on CR likelihood.

Our second aim in Experiment 3 was to assess generalization among brief CSs. There was a decremental generalization gradient in terms of both CR likelihood and $\mathrm{CR}$ amplitude. The gradient was steeper than the flat function suggested by the results of Experiment 2. Clearly, the subjects were not responding solely to stimulus onset but were in fact sensitive to the tonal frequency of the stimulus, even though it was only $50 \mathrm{msec}$ in duration. In the case of the $400-\mathrm{Hz}$ tone, this $\mathrm{CS}$ duration provided only 20 full cycles to the animal. Although the subjects were sensitive to tonal frequency and not just the onset of the CS, there was nevertheless appreciable generalization across the full span of $4400 \mathrm{~Hz}$ between the 4800 and $400-\mathrm{Hz}$ tones. Accordingly, there was ample opportunity for generalization to play a key role in determining CR likelihood and CR timing in Experiments 1 and 2 . As can be seen in the CR timing of Experiment 3's data, when a generalized $C R$ does occur, it retains the timing of the original CR to Stimulus Element A.

\section{GENERAL DISCUSSION}

In all three experiments, manipulation of the stimulus sequence over a 400-msec interval produced large alterations in CR likelihood. More specifically, there were reductions in CR likelihood in both Experiments 1 and 2 when elements in the training CS were removed. There were more modest alterations in CR timing, onset latency, and peak latency. Repetition of a training element in Experiment 3 also had a deleterious effect on CR likelihood but not on CR timing.

Most commonly, the CR was initiated about $250 \mathrm{msec}$ after CS onset and reached a peak about $450 \mathrm{msec}$ after CS 
onset. The largest deviations from this pattern were produced by increasing the interval between successive pulses in Experiment 1. This manipulation yielded a lengthening of the peak latency by 100 msec, a $21 \%$ increase. Conversely, a foreshortening of the CR peak latency around 80 msec was achieved in Experiment 2 when Elements $B, C$, and $D$ from the ascending sequence were presented alone, relative to presentation of the $A$ element by itself.

In broad terms, the sensitivity of CR generation to manipulations in the stimulus series reveals the substantial capacity that the animals have for processing stimulus input over brief time periods, literally in the blink of an eye. Moreover, these results obtained with external stimuli provide evidence that the mechanisms for controlling the evocation and timing of CRs to a conventional delay or trace CS could operate along similar lines. Moreover, the implications of the present results provide some insight into the time course of CR generation. In particular, the available real-time models have identified three key processes that underlie CR generation: (1) the source of the internal representation of the external CS, (2) the learning rules, and (3) the rules for CR performance. On the basis of the present results, it is not possible to favor any one model strongly. Instead, the present results suggest the features of the different models that are most promising.

\section{Source of the Internal Representation}

With regard to the source of the internal CS representation, the models differ slightly in their assumptions regarding the exact role played by the earliest portion of the CS, particularly the role of the stimulus change at CS onset vis à vis the ongoing period of CS presentation. Partly as a simplifying assumption and partly to explain trace conditioning, some models emphasize CS onset as the major source of the internal stimulus sequence (Desmond \& Moore, 1988; Grossberg \& Schmajuk, 1989; Hull, 1943; Klopf, 1988). Other models have emphasized the ongoing portion of the CS as a source of either sustaining energy for the internal representation and/or additional elements for the internal sequence (Gormezano, 1972; Gormezano \& Kehoe, 1981; Sutton \& Barto, 1981, 1990). This emphasis on the ongoing CS helps to keep the internal sequence aligned with the external world and helps to explain the superiority of delay conditioning as opposed to trace conditioning in promoting CR acquisition (Schneiderman, 1966).

The present results clearly indicate that the earliest portion of the CS is a major source of the internal representation. Across all three experiments, the initial element (A) by itself commanded substantial CR-evoking strength and produced a reasonably well-timed $C R$. In the case of trace conditioning in Experiment 3, the initial element was, of course, the sole source of any internal representation. However, it should not be thought that CS onset is sufficient to explain the present findings. As is shown by the generalization gradients in Experiment 3, the sensory features of even a 50-msec CS are processed by the animal. Furthermore, in Experiments 1 and 2, the deleterious effects of subtracting subsequent elements demonstrate a processing of the ongoing CS over intervals of several hundred milliseconds. So too, the deleterious effect of repeating elements in Experiment 3 provides converging evidence for the processing of ongoing stimulus input.

\section{Learning Rules}

The pronounced dominance of the initial element in governing CR topography implies that there was considerable interaction among the elements making up the serial stimulus. Despite the ability of our manipulations to shift CR timing up to $100 \mathrm{msec}$ in either direction, there was nevertheless a strong tendency for the peak of the CR to occur around $450 \mathrm{msec}$ after $\mathrm{CS}$ onset. Even when the sequence of elements was reversed in Experiment 2, the time course of the CR changed in only small ways. Had the elements been independent of one another, the shorter CS-US intervals for elements later in the sequence would have yielded CRs with peaks at correspondingly earlier points when those later elements were tested alone or in reverse order. Instead, the first element seemed to have captured the attention of the animal, and hence, responding to subsequent elements was dictated largely by generalization from the first element.

This primacy effect has been addressed by models in which it is assumed that the successive elements interact both synergistically and competitively. According to Sutton and Barto (1981), primacy effects arise from two sourcesnamely, second-order conditioning between successive CSs, and competition for associative strength between simultaneous CSs. In the Sutton-Barto model, associative strengths are evaluated and altered continuously in accordance with the learning rule now known variously as the delta rule, the least-mean-square rule, the Rescorla-Wagner model, and the Widrow-Hoff rule. According to this rule, alterations in associative strength occur whenever there is a discrepancy between the current output of a system and its recent output. Thus, in a sequence of CSs, an earlier CS (A) with weak associative strength can gain an increment at the onset of a later CS (B) with more associative strength. However, at the point of US onset, the simultaneous representations of $\mathbf{A}$ and $\mathbf{B}$ can both gain associative strength, but only on a competitive basis up to a limit supported by the US. As the associative strengths of $A$ and $B$ rise, their summated strength could exceed the US limit. Thus, at US onset, there could be a negative discrepancy that would produce decrements in the associative strengths of $A$ and $B$. On the next trial, $A$ would regain its lost associative strength at the onset of $B$, while $B$ would continue to suffer decrements in associative strength at US onset until the summated associative strengths of A and B stabilized around the US limit. In summary, through the secondorder conditioning at B's onset, any associative strength acquired by $B$ would be effectively stolen by $A$.

This combination of continuous real-time comparisons and a competitive learning rule does not appear in all realtime models. Desmond and Moore's (1988) model uses a competitive learning rule but has no provision for secondorder conditioning, although one is promised at a later stage of development. Grossberg and Schmajuk's (1989) model 
assumes that there is no competition within the sequence of stimulus elements arising from a single CS. However, their model of real-time CR generation is explicitly meant to be incorporated into a larger network in which primacy effects could emerge for sequences of external stimuli.

\section{CR Generation}

With regard to generating CRs, some models focus on $\mathrm{CR}$ likelihood as a function of temporal manipulations such as the CS-US interval and external serial stimuli (Klopf, 1988; Sutton \& Barto, 1981, 1990). Although they routinely predict anticipatory CRs, these models do not concern themselves with the exact time course of the CR. These models have been successful in explaining and even truly predicting interactions among serial stimuli (Kehoe, Schreurs, \& Graham, 1987). It remains for a more detailed account of the CR's time course to be developed in these models. Other models focus on reproduction of the CR's time course, with less explicit treatment of CR likelihood (Desmond \& Moore, 1988; Grossberg \& Schmajuk, 1989). In these models, CR likelihood can be viewed as a derivative consequence of CR magnitude. For them, CR likelihood simply partitions the CR magnitude on the basis of a criterion-namely, $0.5 \mathrm{~mm}$ in the current experiments. Consequently, the refinement of performance rules, particularly those which include threshold variables, may explain the large variations seen in CR likelihood without dramatic alterations in the timing of the observed CRs.

\section{REFERENCES}

Anderson, N. H. (1959). Response emission in time with applications to eyelid conditioning. In R. R. Bush \& W. K. Estes (Eds.), Studies in mathematical learning theory (pp. 125-134). Stanford, CA: Stanford University Press.

AUGE, R. J. (1977). Stimulus functions within a fixed-interval clock schedule: Reinforcement, punishment, and discriminative stimulus control Animal Leaming \& Behavior, 5, 117-123.

Boyd, T. L., \& LEvis, D. J. (1976). The effects of single-component extinction of a three-component serial CS on resistance to extinction of the conditioned avoidance response. Learning \& Motivation, 7, $517-531$

Chisholm, D. C., Hupka, R. B., \& Moore, J. W. (1969). Auditory differential conditioning of the rabbit nictitating membrane response II. Effects of interstimulus interval and cue similarity. Psychonomic Science, 15, 125-126.

Colavita, F. B. (1965). Dual function of the US in classical salivary conditioning. Joumal of Comparative \& Physiological Psychology, 60, 218-222.

Coleman, S. R., Gormezano, I. (1971). Classical conditioning of the rabbit's (Oryctolagus cuniculus) nictitating membrane response under symmetrical CS-US interval shifts. Joumal of Comparative \& Physiological Psychology, 29, 587-612.

DESMOND, J. E., MOORE, J. W. (1988). Adaptive timing in neural networks: The conditioned response. Biological Cybernetics, 58, 405-415.

DUBIN, W. J., \& LEVIS, D. J. (1973). Influence of similarity of components of a serial conditioned stimulus on conditioned fear in rats. Journal of Comparative \& Physiological Psychology, 85, 304-312.

EGger, D. M., \& Miller, N. E. (1962). Secondary reinforcement in rats as a function of information value and reliability of the stimulus. Joumal of Experimental Psychology, 64, 97-104.

ELuson, G. D. (1964). Differential salivary conditioning to traces. Joumal of Comparative \& Physiological Psychology, 57, 373-380.

FERSTER, C. B., \& SKINNER, B. F. (1957). Schedules of reinforcement. New York: Appleton-Century-Crofts.
GAIONI, S. J. (1982). Blocking and nonsimultaneous compounds: Comparison of responding during compound conditioning and testing. Pavlovian Journal of Biological Sciences, 17, 16-29.

Gormezano, I. (1966). Classical conditioning. In J. B. Sidowski (Ed.). Experimental methods and instrumentation in psychalogy (pp. 385-420). New York: McGraw-Hill.

Gormezano, 1. (1972). Investigations of defense and reward conditioning in the rabbit. In A. H. Black \& W. F. Prokasy (Eds.), Classical conditioning II: Current research and theory (pp. 151-181). New York: Appleton-Century-Crofts.

Gormezano, I., \& GibBs, C. M. (1988). Transduction of the rabbit's nictitating membrane response. Behavior Research Methods, Instruments, \& Computers, 20, 18-21.

GormezANO, I., KeHOE, E. J. (1981). Classical conditioning and the law of contiguity. In P. Harzem \& M. D. Zeiler (Eds.), Adwances in analysis of behavior: Vol. 2. Predictability, correlation, and contiguity (pp. 1-45). Sussex, England: Wiley.

Gormezano, I., Kehoe, E. J., \& Marshall, B. S. (1983). Twenty years of classical conditioning research with the rabbit. In J. M. Sprague \& A. N. Epstein (Eds.), Progress in psychobiology and physiological psychology (Vol. 10, pp. 197-275). New York: Academic Press.

Grossberg, S., Schmajuk, N. A. (1989). Neural dynamics of adaptive timing and temporal discrimination during associative leaming. Neural Networks, 2, 79-102.

HOEHLER, F. K., LEONARD, D. W. (1976). Double responding in classical nictitating membrane conditioning with single-CS, dual-ISI pairing. Pavlovian Joumal of Biological Science, 11, 180-190.

Hol.LAND, P. C., R Ross, R. T. (1981). Within-compound associations in serial compound conditioning. Joumal of Experimental Psychology: Animal Behavior Processes, 7, 228-241.

Hull, C. L. (1937). Mind, mechanism and adaptive behaviors. Psychological Review, 44, 1-32.

HuLl, C. L. (1943). Principles of behavior. New York: Appleton.

KEHOE, E. J. (1979). The role of CS-US contiguity in classical conditioning of the rabbit's nictitating membrane response to serial stimuli. Learning \& Motivation, 10, 23-38.

KEHOE, E. J. (1982). Conditioning with serial compound stimuli: Theoretical and empirical issues. Experimental Animal Behavior, 1, 30-65

KeHOE, E. J., FEYER, A.-M., \& Moses, J. L. (1981). Second-order conditioning of the rabbit's nictitating membrane response as a function of the CS2-CS1 and CS1-US intervals. Animal Learning \& Behavior, 9. 304-315.

Kehoe, E. J., Marshall-Goodell, B. S., \& Gormezano, I. (1987) Differential conditioning of the rabbit's nictitating membrane response to serial compound stimuli. Joumal of Experimensal Psychology: Animal Behavior Processes, 13, 17-30.

Kehoe, E. J., SChreurs, B. G., Graham, P. (1987). Temporal primacy overrides prior training in serial compound conditioning of the rabbit's nictitating membrane response. Animal Leaming \& Behavior, 15, 455-464.

Kehoe, E. J., Graham-Clarke, P., Schreurs, B. G. (1989). Temporal patterns of the rabbit's nictitating membrane response to compound and component stimuli under mixed CS-US intervals. Behavional Neuroscience, 103, 283-295.

KIMMEL, H. D. (1965). Instrumental inhibitory factors in classical conditioning. In W. F. Prokasy (Eds.), Classical conditioning (pp. 148171). New York: Appleton.

KLopf, A. H. (1988). A neuronal model of classical conditioning. Psychobiology, 16, 85-125.

MatThews, T. J., \& Lerer, B. E. (1987). Behavior patterns in pigeons during autoshaping with an incremental conditioned stimulus. Animal Leaming \& Behavior, 15, 69-75.

Millenson, J. R., Kehoe, E. J., \& Gormezano, I. (1977). Classical conditioning of the rabbit's nictitating membrane response under fixed and mixed CS-US intervals. Learning \& Motivation, 8, 351-366.

MOORE, J. W. (1972). Stimulus control: Studies of auditory generalization in rabbits. In A. H. Black \& W. F. Prokasy (Eds.), Classical conditioning II: Current research and theory (pp. 151-181). New York: Appleton-Century-Crofts.

NEWLiN, R. J., \& LoLoRDo, V. M. (1976). A comparison of pecking generated by serial, delay, and trace autoshaping procedures. Journal of the Experimental Analysis of Behavior, 25, 227-241. 
PAlya, W. A. (1985). Sign-tracking with an interfood clock. Journal of the Experimental Analysis of Behavior, 43, 321-330.

PAvlov, I. P. (1927). Conditioned reflexes (G. V. Anrep, Ed. and Trans.). London: Oxford University Press.

Poulos, C. X., Kehoe, E. J., \& Gormezano, I. (1985). Appetitive differential conditioning of the rabbit's jaw movement response: Effects of cue similarity and US magnitude. Pavlovian Joumal of Biological Science, 20, 29-38.

ResCorla, R. A. (1982). Effect of a stimulus intervening between CS and US in autoshaping. Journal of Experimental Psychology: Animal Behavior Processes, 8, 131-141.

Salafia, W. R., Martino, L. J., Cloutman, K., Romano, A. G. (1979). Unconditional-stimulus locus and interstimulus-interval shift in rabbit (Oryctolagus cuniculus) nictitating membrane conditioning. Pavlovian Journal of Biological Science, 14, 64-71.

SCANDRETT, J., \& GoRmezANO, I. (1980). Microprocessor control and A/D data acquisition in classical conditioning. Behavior Research Methods \& Instrumentation, 12, 120-125.

SCHNEIDERMAN, N. (1966). Interstimulus interval function of the nictitating membrane response in the rabbit under delay versus trace conditioning. Joumal of Comparative \& Physiological Psychology, 62, 397-402.

SMITH, M. C. (1968). CS-US interval and US intensity in classical conditioning of the rabbit's nictitating membrane response. Joumal of Comparative \& Physiological Psychology, 66, 679-687.

Smith, M. C., Coleman, S. R., \& Gormezano, I. (1969). Classical conditioning of the rabbit's nictitating membrane response at backward, simultaneous, and forward CS-US intervals. Journal of Comparative \& Physiological Psychology, 69, 226-231

Suboski, M. D. (1967). UCS intensity and the latency of the classically conditioned eyelid response. Joumal of Experimental Psychology, 74, 31-35.

SUTTON, R. S., \& BARTo, A. G. (1981). Toward a modern theory of adaptive networks: Expectation and prediction. Psychological Review, $88,135-171$.

Sutton, R. S., \& Barto, A. G. (1990). Time-derivative models of Pavlovian reinforcement. In M. Gabriel \& J. W. Moore (Eds.), Learning and computational neuroscience (pp. 497-537). Cambridge, MA: MIT Press.

WICKENS, D. D. (1959). Conditioning to complex stimuli. American Psychologist, 14, 180-188.

WICKENS, D. D. (1965). Compound conditioning in humans and cats. In A. H. Black \& W. F. Prokasy (Eds.), Classical conditioning II: Current research and theory (pp. 151-181). New York: Appleton-CenturyCrofts.

WILSON, R. S. (1969). Cardiac response: Determinants of conditioning. Journal of Comparative \& Physiological Psychology Monographs, 68(No. 1, Pt. 2), 1-23.

(Manuscript received June 27, 1990; revision accepted for publication March 1, 1991.) 